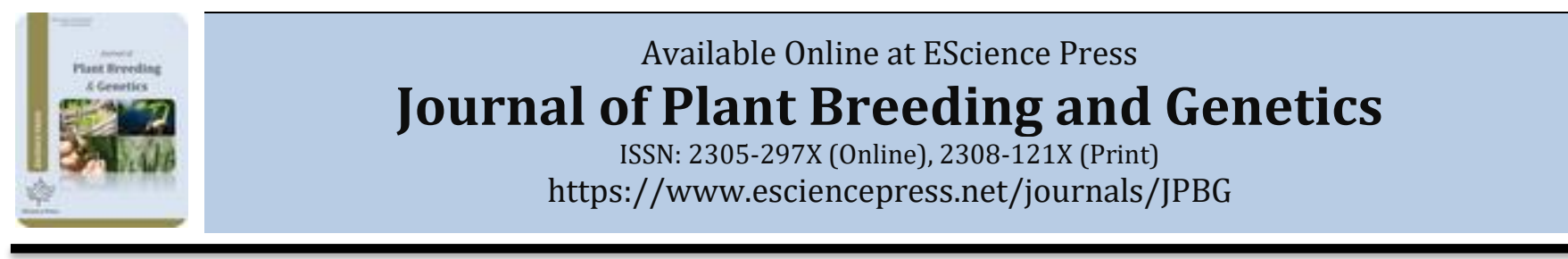

\title{
GENETIC STRUCTURE AND DIVERSITY IN SORGHUM BICOLOR (L.) MOENCH LANDRACES FROM MARGINAL SORGHUM PRODUCTION LANDS IN SENEGAL, BASED ON SSR MARKERS
}

\author{
${ }^{a} A m y$ Bodian, bBassiaka Ouattara, a,cAwa Sarr, a,cBoubacar Gano, aMbaye-Ndoye Sall, dKhadidiatou-Ndoye Ndir, \\ aNdiaga Cissé, eHamidou Falalou \\ a Centre d'Etude Régional pour l'Amélioration de l'Adaptation à la Sécheresse (CERAAS), Institut Sénégalais de \\ Recherches Agricoles (ISRA), Thiès, Sénégal. \\ b Université de Fada N'Gourma (U-FDG), Fada N'Gourma, Burkina Faso. \\ c Laboratoire Campus de Biotechnologies Végétales, Faculté des Sciences et Techniques, Université Cheikh Anta Diop \\ (UCAD), Dakar Fann, Dakar, Sénégal. \\ d Département de Productions Végétales, Ecole Nationale Supérieure d'Agriculture (ENSA), Université deThiès, Thiès, \\ Sénégal. \\ e ICRISAT Sahelian Center, Niamey, Niger.
}

Corresponding Author Email: miamybo@yahoo.fr

\section{A B S T R A C T}

Data on sorghum genetic diversity in Senegal are missing despite its importance in the food and feed in the country. In order to contribute to the sustainable in situ management of sorghum germplasm, we investigated its genetic diversity and structure in its marginal production areas. Investigations were focused on Thiès, Diourbel and Kédougou regions where sorghum landraces have been less investigated and genetic information on landraces is unknown. A total of 148 sorghum accessions representative of landraces used in production systems have been sampled and analyzed with 30 microsatellite markers. A total of 138 alleles have been recorded. The number of alleles per locus varied from 3 (7 loci) to 8 ( 3 loci). The observed heterozygosity varied from 0 to 0.62 . The low genetic distance (0.12) was recorded between Thiès and Diourbel populations and the highest distance $(0.22)$ between Thiès and Kédougou populations. Dendrogram obtained according to Neighbour joining classification model allowed the classification of sorghum accessions into three main groups. The Genetic structure is not function to the regions indicating that landraces are not specific to a region. The results are a first step toward the sustainable in situ management of genetic resources. Data on the whole range of existing diversity of sorghum in Senegal is an important key for its germplasm management; so, the genotyping must be extended to accessions from the whole country.

Keywords: sorghum, landraces, diversity, microsatellite markers, Senegal.

\section{INTRODUCTION}

Sorghum (Sorghum bicolor ssp bicolor L. Moench.) is one of the major staple food and fodder crop in semi-tropical Africa and Asia (Doggett, 1988) maybe because of its unusual tolerance of hot and dry environments (Mullet $e t$ al., 2002). In Senegal, sorghum is one of the farmer's principal cereal crops (ANSD, 2010; Ba et al., 2010). The most important sorghum production areas according to ANSD (2018) are Kaffrine, Tambacounda, Sédhiou regions. Five major races or sorghum (bicolor, caudatum, dura, guinea and Kafir) have been identified in the World according to panicle and spikelet morphology (Harlan and de Wet, 1976). Sorghum bicolor subsp. bicolor constitutes the cultivated form and exhibits great phenotypic variability. The cultivated form is mainly cross-pollinated. The frequency of outcrossing varied from 5 to 40 percent in the open field (Barnaud et al., 2008).

Many studies in the world have investigated the patterns of genetic diversity among sorghum accessions. Some studies have demonstrated that genetic structuration is associated with geographic origin and racial classification (Deu et al., 2006). However, other studies showed a lack of 
association between genetic structure and geographic origin or racial groups (Menkir et al., 1997; Djé et al., 2000). Unfortunately, such information is missing in Senegal. Until now, the prospection and collect of sorghum cultivars in Senegal concerned mainly the Sine Saloum, Casamance, Tambacounda, Ferlo and Senegal River, areas known since a long time as zones of sorghum production. A total of 242 accessions have mainly been collected in these regions between 1974 and 2002 and brought in genes bank at ICRISAT/India. This sampling has been an important action in landraces conservation. However, in this previous collection, there is only 1 sample from Thies, 2 from Kédougou. So, it is expected that a thorough sampling of sorghum landraces in Thiès, Diourbel and Kédougou regions in Senegal could give additional information on this crop and allow extending the conservation action to landraces specifics to these zones. Indeed, the adoption of improved varieties is generally limited in the country. The largest part of sorghum production comes from farmerselected landraces, especially in marginal production lands. These landraces are adapted to the local environments. It is also well known that contrasting sorghums with contrasting adaptation are often grown in the rainy season and post-rainy season within the same geographic region (Deu et al., 2006). Moreover, ethnic traditions, social organizations and food preferences also probably could contribute to the extent and structure of crop diversity in these regions (Reenberg 2001; Deu et al., 2008). The geographical distribution of landrace vernacular names, agromorphological types and genetic diversity on different spatial scales also provides valuable information to complement ex situ collections and establish relevant criteria to initiate and monitor in situ conservation programs (Brush, 2000). Genetic information on landraces prevalent in Senegal regions with low interest for sorghum cultivation will be an important input for further breeding programs and sorghum promoting projects interested in these areas. For these reasons, the study aims to characterize genetic diversity and spatial structure of sorghum landraces prevalent in Senegal zones with low interest for sorghum cultivation as the first step for future in situ conservation programs. The present study is part of global research activities at the national level since 2013 to improve major crops and to better manage germplasm resources in Senegal.

\section{MATERIAL AND METHODS}

An intensive collection of sorghum accessions was conducted in 16 villages belonging to Thiès, Diourbel and Kédougou regions in Senegal (figure 1). Villages were distant at least $20 \mathrm{Km}$ and far from roads to avoid anthropic effects. In each village, 6 to 14 farmers have been interviewed individually and in focus groups. The survey included information on crop uses, seed origins, agricultural systems, desired varieties, etc. In each village, we sampled all local varieties listed by farmers. Sampling has been done either in farmers' fields, in panicle-drying zones or in-home granaries, depending on the advancement of harvest work.

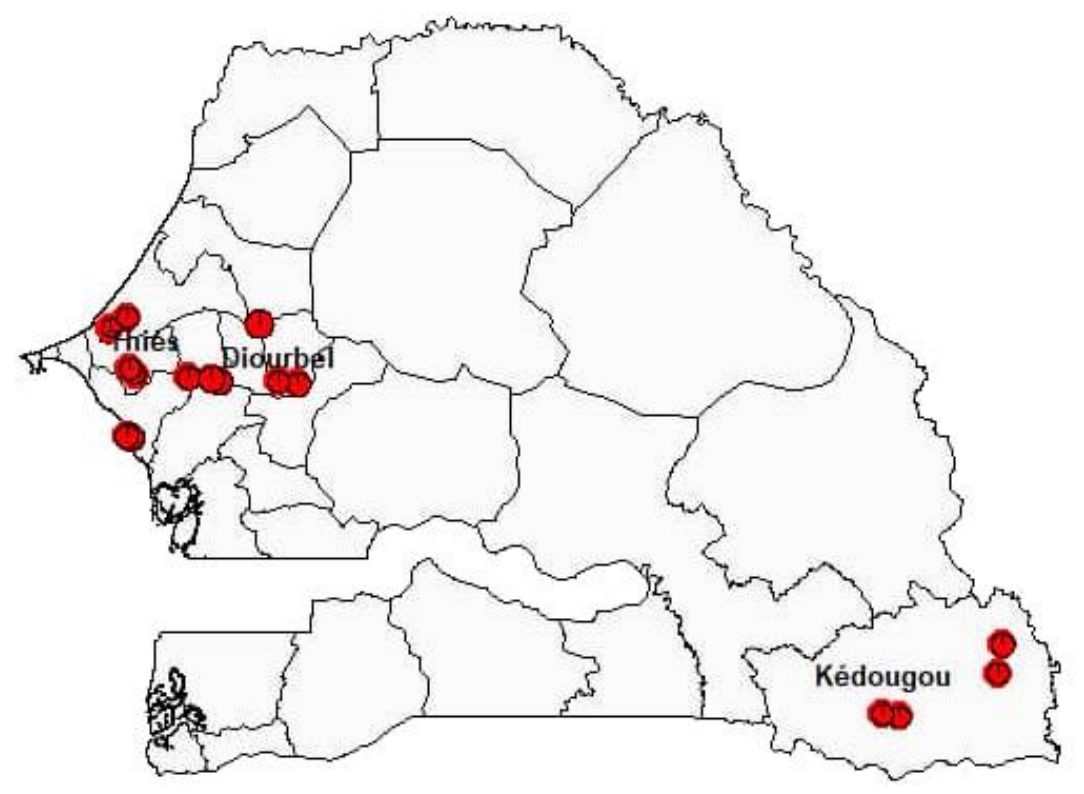

Figure 1. Sites of collect. 
Table 1. List of regions, departments and villages where sorghum accessions have been sampled.

\begin{tabular}{|c|c|c|c|c|}
\hline Regions & Departments & Villages & Accession number/village & Accession number/region \\
\hline \multirow{6}{*}{ Thiès } & \multirow{2}{*}{ Thiès } & Keur Birane & 6 & \multirow{6}{*}{50} \\
\hline & & Taten Bambara & 8 & \\
\hline & \multirow{2}{*}{ Tivaoune } & Pambal Boye & 8 & \\
\hline & & Ndiaye Bope & 6 & \\
\hline & \multirow{2}{*}{ Mbour } & Keur Coly & 10 & \\
\hline & & Keur Cheikh & 12 & \\
\hline \multirow{6}{*}{ Diourbel } & \multirow{2}{*}{ Bambey } & Touba Ndjemane & 9 & \multirow{6}{*}{64} \\
\hline & & Ndione & 12 & \\
\hline & \multirow{2}{*}{ Mbacké } & Koffa & 8 & \\
\hline & & SéoTienene & 10 & \\
\hline & \multirow{2}{*}{ Diourbel } & Mboule Mbapp & 14 & \\
\hline & & Gnignakh & 11 & \\
\hline \multirow{4}{*}{ Kédougou } & \multirow{2}{*}{ Saraya } & Kondokhou & 8 & \multirow{4}{*}{34} \\
\hline & & Missirah Sirimana & 10 & \\
\hline & \multirow{2}{*}{ Kédougou } & Barafoute & 8 & \\
\hline & & Baraboye & 8 & \\
\hline
\end{tabular}

Table 2. Characteristics of the microsatellite primers used.

\begin{tabular}{lllcc}
\hline $\begin{array}{c}\text { Marker } \\
\text { names }\end{array}$ & \multicolumn{1}{c}{ Primer sequence $\mathrm{F}$} & \multicolumn{1}{c}{ Primer sequence R } & $\begin{array}{c}\text { Expected } \\
\text { Size }(\mathrm{bp})\end{array}$ & $\begin{array}{c}\text { Annealing } \\
\text { Temperature }\left({ }^{\circ} \mathrm{C}\right)\end{array}$ \\
\hline $\begin{array}{l}\text { gpsb112 } \\
\text { gpsb121 }\end{array}$ & GTCTAACTCCTCGCTCC & TCCAACAAAATCCACC & 209 & 50 \\
gpsb127 & CGCATCGTAGTTGTTG & GCAGCATTTCTGGAGT & 157 & 50 \\
gpsb128 & CACGCGACCGTAAAG & GATAAGGTGATGGAGGAAA & 189 & 50 \\
gpsb129 & CTCAACTCAACGCCTAC & ACTACTCCAATCCAATCC & 264 & 50 \\
gpsb015 & CGTTCGTTCATTTCTCTTTC & GCTCTGGGCGTCTGAT & 257 & 50 \\
gpsb158 & GAATTGAGTGGGATTTT & GTCAGAGAATGGGTTCAT & 187 & 50.5 \\
gpsb170 & ATAAATCCTTGCGTCCT & CCTAAACTTCCCTTTCT & 283 & 50 \\
gpsb176 & TAATTCTAGTCATCACCCC & TTGGCGTTCATAGTTTC & 239 & 50 \\
gpsb180 & TCATTTGTAGTTGCGTTAG & GCTTTCACTTGGGGA & 273 & 50 \\
gpsb050 & GGCTTCTTTCCTCTCC & GAGTTCTTTTATGTTTTGTGT & 160 & 50 \\
gpsb051 & TGAAGGACTTTGATACCC & CCTAAGACTGCCAATGTT & 177 & 49 \\
gpsb063 & CATCATGGTTTGTGT & CTGCTCATTTTATCGTC & 177 & 49 \\
gpsb067 & TAGTCCATACACCTTTCA & TCTCTCACACACATTCTTC & 178 & 50 \\
gpsb079 & AGGACAGAACAGGAAGG & GTGAATTTGATTGGAAAG & 151 & 49.1 \\
gpsb095 & TACTACAGGGGCTTGG & GTGTGGGAAGAGGGA & 178 & 50 \\
gpsb123 & ATAGATGTTGACGAAGCA & GTGGTATGGGACTGGA & 304 & 50 \\
mSbCIR230 & AACAATCGACCCTTCCTAAC & TCTTGTTCATGTGCCAGTAG & 110 & 50 \\
msbcir238 & AGAAGAAAAGGGTAAGAGC & CGAGAAACAATTACATGAACC & 105 & 55.2 \\
mSbCIR242 & GGATGAATAAATCGGGTTG & GAAACAAAATACCCAGCAGT & 101 & 54.7 \\
mSbCIR248 & GTTGGTCAGTGGTGGATAAA & ACTCCATGTGCTGAATCT & 101 & 54.9
\end{tabular}




\begin{tabular}{llllc} 
mSbCIR286 & GCTTCTATACTCCCCTCCAC & TTTATGGTAGGATGCTCTGC & 112 & 55.5 \\
mSbCIR311 & GATCTCACATTGCTTGTTT & TGAGCTTCTCCACATTCT & 112 & 51 \\
mSbCIR313 & AACGTACCACACGTATTTGA & TCTTGTGCTCGTAGAGTGTC & 140 & 54 \\
mSbCIR323 & CTTGAACCCCACTCAAGAC & TACCTGCACTGCTGCTTC & 284 & 55.8 \\
msbcir347 & GAACATCAGAGGGTTTACCA & GAACCAACTACGCTTGTGTC & 118 & 55.4 \\
SbAGB02 & CTCTGATATGTCGTTGTGCT & ATAGAGAGGATAGCTTATAGCTCA & 119 & 62 \\
Xcup11 & TACCGCCATGTCATCATCAG & CGTATCGCAAGCTGTGTTTG & 204 & 60 \\
Xcup14 & TACATCACAGCAGGGACAGG & CTGGAAAGCCGAGCAGTATG & 210 & 62 \\
Xcup61 & TTAGCATGTCCACCACAACC & AAAGCAACTCGTCTGATCCC & 237 & 60 \\
Xcup63 & GTAAAGGGCAAGGCAACAAG & GCCCTACAAAATCTGCAAGC & 185 & 60 \\
\hline
\end{tabular}

\section{DNA isolation}

Genomic DNA was extracted using a modified MATAB (Mixed Alkyl Trimethyl Ammonium Bromide) extraction method (Risterucci et al., 2000). Twenty (20) mg of dried leaves were ground (MM301, Retsch). The crushed material was transferred to a $2 \mathrm{ml}$ Eppendorf tube containing $750 \mu \mathrm{l}$ of $2 \%$ MATAB extraction buffer solution preheated to $65{ }^{\circ} \mathrm{C}$. The mixture was homogenized for 20 seconds and then incubated in a water bath for $20 \mathrm{~min}$ with stirring every $5 \mathrm{~min}$. After cooling to room temperature for $5 \mathrm{~min}, 750 \mu \mathrm{l}$ of Chloroform Isoamyl Alcohol (CIAA) was added to the mixture, homogenized, then centrifuged at $13000 \mathrm{rpm}$ for $20 \mathrm{~min}$ at $20{ }^{\circ} \mathrm{C}$. The supernatant $(600 \mu \mathrm{l})$ was removed and transferred to new $1.5 \mathrm{ml}$ tubes containing an equivalent volume of cold isopropanol. The pellet of the DNA was precipitated at $-20{ }^{\circ} \mathrm{C}$ for $2 \mathrm{~h}$ and then centrifuged at $13000 \mathrm{rpm}$ for $20 \mathrm{~min}$ at $4{ }^{\circ} \mathrm{C}$. After removing the supernatant, the pellet was cleaned with $500 \mu \mathrm{l}$ of $70 \%$ ethanol, centrifuged at $13000 \mathrm{rpm}$ for 20 $\min$ at $4{ }^{\circ} \mathrm{C}$. This supernatant was removed, and the pellet dried for at least $1 \mathrm{~h}$ at room temperature before being dissolved in $150 \mu \mathrm{l}$ of $1 \mathrm{X}$ TE during $2 \mathrm{H}$.

The DNA was quantified by migration in a $1 \%$ agarose (Lonza) gel containing 0.5 X TBE (Tris Borate EDTA); 2.5 $\mu \mathrm{l}$ of BET (Ethidium bromide) $(0.5 \mathrm{mg} / \mu \mathrm{l})$. The samples to be deposited were prepared by mixing $2 \mu \mathrm{l}$ of DNA, $2 \mu \mathrm{l}$ of bromophenol blue and $6 \mu \mathrm{l}$ of ultrapure water. The gel was migrated at 100 volts for $30 \mathrm{~min}$ and then photographed under UV at $230 \mathrm{~nm}$ using a UV table (UVITEC). DNA yields were determined by concentration estimation, compared to the bands of a Smart Ladder (Eurogentec) of known concentration and diluted to a working concentration of $5 \mathrm{ng} / \mathrm{ul}$.
Microsatellites amplification and electrophoresis

A PCR was carried out using 30 sorghum SSR markers (Table 2) previously used by Barnaud et al. (2008). PCR reactions were performed in a total reaction mixture of $10 \mu \mathrm{l}$ containing: $25 \mathrm{ng}$ template DNA; $1 \mu \mathrm{l}$ of PCR buffer $10 \mathrm{X} ; 2.0 \mathrm{mM} \mathrm{MgCl}$; $0.2 \mathrm{mM} \mathrm{dNTP} ; 0.06 \mu \mathrm{M}$ of the universal Cy5-labeled; $0.08 \mu \mathrm{M}$ of M13-tailed forward primer at the 5 'end (Schuelke, 2000), (F); $0.1 \mu \mathrm{M}$ of reverse primer (R); $0.5 \mathrm{U}$ of Taq DNA polymerase (Tina Taq). Amplifications were performed using an MJ Research PTC 200 thermal cycler (Bio-Rad Laboratories Inc.) with the following cycle profile: initial denaturation for $1 \mathrm{~min}$ at $95^{\circ} \mathrm{C}$ followed by 35 cycles with $30 \mathrm{sec}$ at $94^{\circ} \mathrm{C}, 1 \mathrm{~min}$ at primer-specific annealing temperature (Table 2), $2 \mathrm{~min}$ at $72^{\circ} \mathrm{C}$ and a final extension step at $72^{\circ} \mathrm{C}$ for $8 \mathrm{~min}$. All PCR products were separated on a $6,5 \%$ polyacrylamide denaturing gel using a LICOR 4300 sequencer by loading $2 \mu \mathrm{l}$ of PCR product diluted $4 \mathrm{X}$ in loading buffer.

\section{SSR data analysis}

The average number of alleles per locus, the expected heterozygosity ( $\mathrm{He}$ ) and the observed heterozygosity (Ho) per marker were calculated using R 3.6.0 software ( $\mathrm{R}$ Core Team, 2019). $\mathrm{R}$ also allows computing the fixation index or F-statistic (Fst) to assess the differentiation of gene pool of the 3 regions investigated. The genetic distances and the analysis of molecular variance (AMOVA) were also calculated using GenAlex 6.501 (Peakall and Smouse, 2012) software. DARwin 6 (Perrier and Jacquemoud-Collet, 2006) software was used to make the dendrogram. Genetic population structure was inferred with the structure software (Pritchard et al., 2000). The analysis was performed with $\mathrm{K}$ ancestral populations ranging from 1 to 10 with 500000 iterations and a burn-in period of 100000 . Ten 
(10) runs for each K-value were performed and outputs were summarized using Structure Harvester (Earl and vonHoldt, 2012). We evaluated the number of population K based on Evanno's method. For ancestry analysis (q), we used the simulation with the highest log probability. We classified individuals in groups based on an ancestry coefficient of 0.7 or higher.

\section{RESULTS}

\section{Microsatellite amplification}

The 30 microsatellite markers used, gave good amplification of DNA. Figure 2 shows an example of a polyacrylamide gel.

\section{Allele number and percentage of polymorphic loci}

All the loci were polymorphic and the number of alleles per locus varied from 3 (7 loci) to 8 (3 loci) as presented in table 3. A total of 138 alleles have been recorded corresponding to an average of 4.6 alleles per locus.

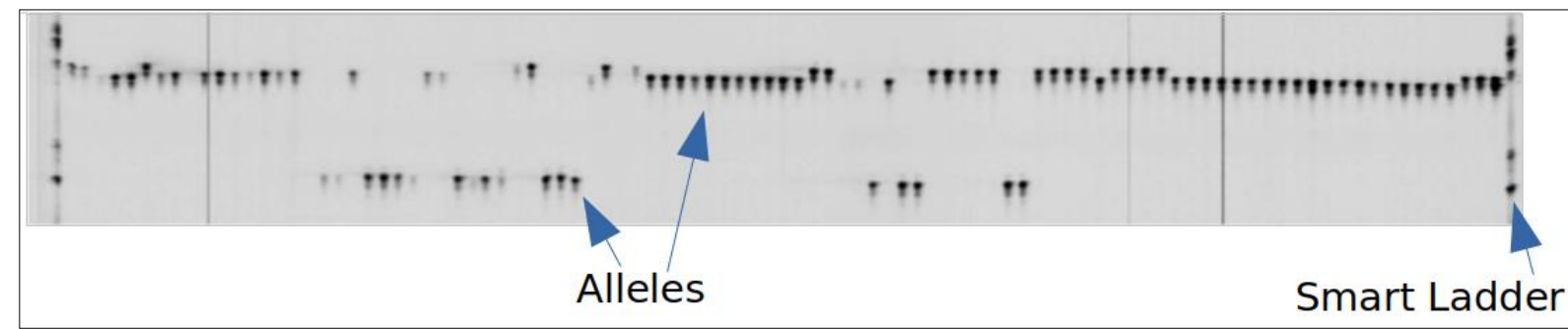

Figure 2. Revelation on polyacrylamide gel of the locus msbcir347 in sorghum population.

Table 3. Number of alleles per locus.

\begin{tabular}{llllllll}
\hline Locus & Nb allele & Ho & He & Locus & Nb allele & Ho & He \\
\hline xcup 11 & 5 & 0.32 & 0.74 & gpsb 127 & 4 & 0.11 & 0.71 \\
xcup 63 & 6 & 0.03 & 0.78 & gpsb 121 & 5 & 0.06 & 0.69 \\
sgagb 02 & 6 & 0.14 & 0.74 & msbcir 248 & 3 & 0.11 & 0.51 \\
msbcir 242 & 5 & 0.14 & 0.62 & msbcir 311 & 4 & 0 & 0.68 \\
gpsb123 & 6 & 0.62 & 0.82 & msbcir 313 & 4 & 0.02 & 0.56 \\
gpsb 79 & 3 & 0.04 & 0.52 & MSBCIR 323 & 4 & 0 & 0.72 \\
gpsb 95 & 3 & 0.03 & 0.46 & gpsb 67 & 4 & 0.14 & 0.64 \\
msbcir 347 & 8 & 0.02 & 0.63 & gpsb 15 & 6 & 0.16 & 0.82 \\
gpsb 180 & 4 & 0.02 & 0.67 & xcup 61 & 3 & 0.07 & 0.65 \\
xcup 14 & 8 & 0.06 & 0.81 & gpsb 50 & 8 & 0.03 & 0.8 \\
gpsb 112 & 4 & 0.1 & 0.73 & gpsb 63 & 4 & 0.01 & 0.63 \\
gpsb 176 & 3 & 0.05 & 0.66 & gpsb 51 & 4 & 0.09 & 0.69 \\
gpsb 170 & 3 & 0.08 & 0.64 & msbcir 286 & 5 & 0.08 & 0.69 \\
gpsb 158 & 3 & 0 & 0.51 & gpsb 129 & 5 & 0.09 & 0.58 \\
gpsb 128 & $\underline{4}$ & $\underline{0.13}$ & $\underline{0.49}$ & $\underline{\text { msbir 230 }}$ & $\underline{4}$ & $\underline{0.04}$ & $\underline{0.74}$ \\
\hline
\end{tabular}

Nb allele: number of alleles; Ho: observed heterogeneity; He: expected heterogeneity.

\section{Observed and expected heterozygosity per locus and per population}

Three loci (Gpsb158; Msbcir311; Msbcir323) have a null value of observed heterozygosity and the highest value was recorded with gpsb123 (Ho = 0.62). The expected heterozygosity varied from 0.46 (gpsb95) to 0.82 (gpsb123; gpsb15) as showed in table 3 . The highest observed heterozygosity (Ho) was recorded in Kédougou population whereas the highest expected heterozygosity (He) was recorded in Diourbel population (Table 4). In all the populations, the He was at least six times higher compared to the corresponding Ho.

\section{Genetic distances}

The low Nei's genetic distance (0.12) was recorded 
between Thiès and Diourbel populations and the highest distance (0.22) between Thiès and Kédougou populations.

\section{Genetic differentiation index}

Fst values are ranged from 0.03 to 0.06 (table 6). Low Fst values were recorded when comparing sorghum populations from Thiès and Diourbel, Diourbel and Kédougou. Kédougou and Thiès populations show moderate Fst.

\section{Analysis of molecular variance}

An analysis of the molecular variance (AMOVA) was performed using the matrix of distances for genetic differentiation. The overall genetic variation has been divided among pops (regions) (6\%), among individuals within regions (84\%), and within individuals (11\%). The results obtained showed that the diversity within pops (intra-regional diversity) was greater than the diversity between pops (inter-regional diversity) (Table 7).

Table 4. Observed and expected heterozygosity per population.

\begin{tabular}{lccc}
\hline Populations & Ho & He & F \\
\hline Diourbel & 0.094 & 0.655 & 0.859 \\
Thiès & 0.084 & 0.62 & 0.876 \\
Kédougou & 0.109 & 0.6 & 0.82 \\
\hline
\end{tabular}

Ho: observed heterogeneity, He: expected heterogeneity; F: Wright's F-statistics.

Table 5. Nei's Genetic distances considering the region of sampling.

\begin{tabular}{lcc}
\hline & Diourbel & Thiès \\
\hline Thiès & 0.12 & \\
Kédougou & 0.167 & 0.221 \\
\hline
\end{tabular}

Table 6. Fst values according to regions.

\begin{tabular}{lcc}
\hline & Diourbel & Thiès \\
\hline Thiès & $0.028(\mathrm{p}$-value 0.0198$)$ & \\
Kédougou & $0.039(\mathrm{p}$-value $=0.0099)$ & $0.057(\mathrm{p}$-value $=0.0099)$ \\
\hline
\end{tabular}

Table 7. Analysis of molecular variances.

\begin{tabular}{lccccc}
\hline Source & df & SS & MS & Est. Var. & $\%$ \\
\hline Among Pops & 2 & 161.781 & 80.89 & 0.636 & $6 \%$ \\
Among Indiv & 145 & 2905.52 & 20.038 & 9.416 & $84 \%$ \\
Within Indiv & 148 & 178.5 & 1.206 & 1.206 & $11 \%$ \\
Total & 295 & 3245.801 & & 11.258 & $100 \%$ \\
\hline
\end{tabular}

Df: degree of freedom; SS: sum of square; MS: mean of square; Est.Var: estimated variance.

\section{Dendrogram}

Neighbour joining cluster analysis of genomic SSR genetic diversity matrix resulted in the dendrogram represented in figure 3. The dendrogram allows distinguishing three main groups. The similarity dendrogram (Figure 3) showed 3 main groups (a, b and c). Fifty six (56) individuals constitute the group a, 70 for $\mathrm{b}$ and 22 individuals for the group c. Each group includes individuals from the three regions where sorghum was sampled. However, group c includes only 2 individuals from Thiès. In group a, we distinguish 2 subgroups; one subgroup includes only individuals from Diourbel. 


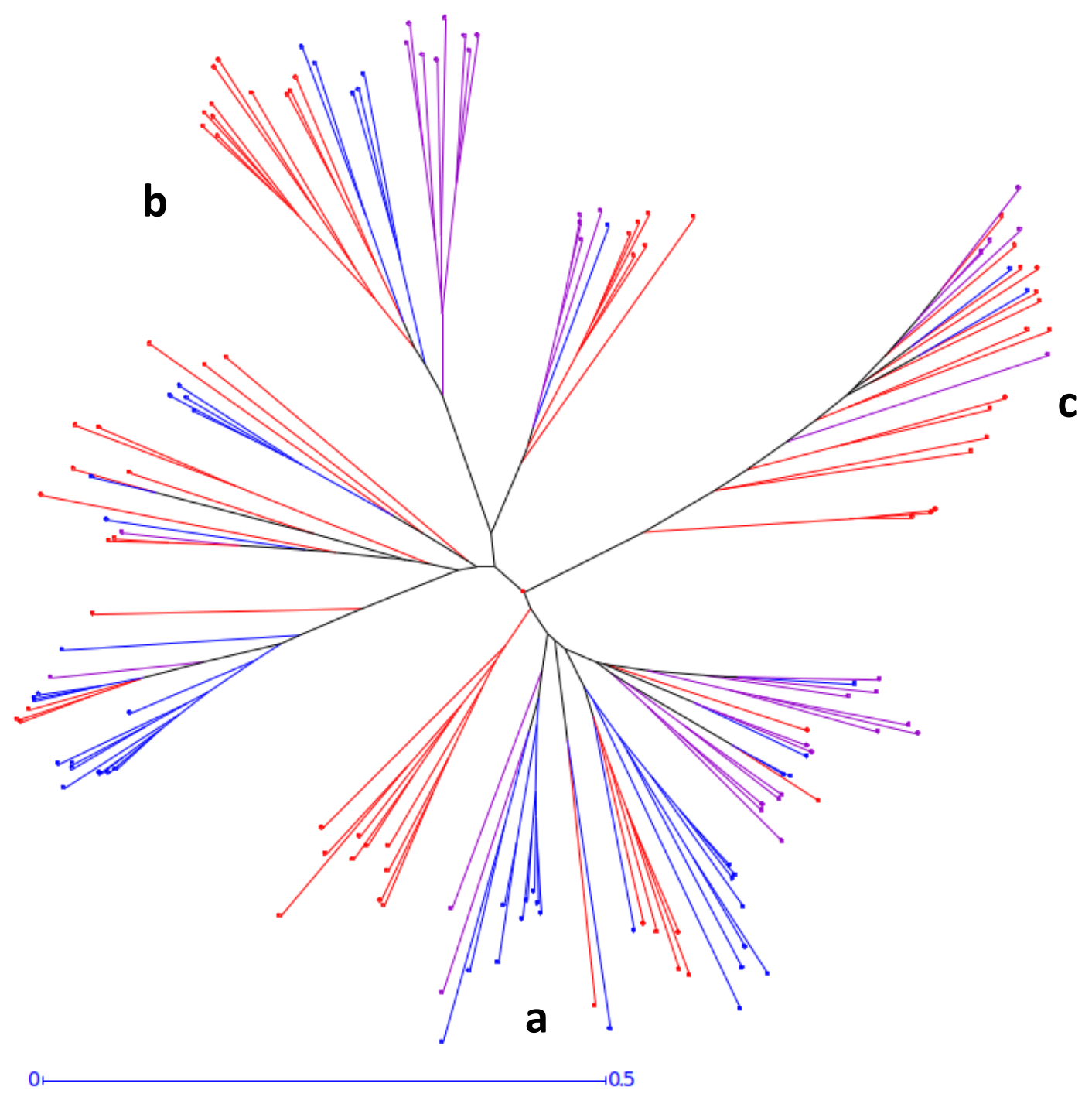

Figure 3. Dendrogram of similarity based on SSR markers. legend:

individuals sampled in Diourbel
individuals sampled in Thiès
individuals sampled in Kédougou

\section{Structure analysis}

STRUCTURE was able to correctly identify the number of subpopulations at Fst around 0.03 the most probable value of $\mathrm{K}$ was 4 .

The structuring without a priori of the accessions was done with an ADMIXTURE analysis (Figure 4). This model based on the estimation of the membership coefficient was used to determine the optimal number of groups in the collection. Thus, the accessions were divided into four (4) groups. Group I is in the majority with 65 accessions
(59 from Diourbel and 6 from Thiès), followed by group II with 31 accessions, all from Thiès. Groups III and IV are in the minority with 20 and 27 accessions respectively. The first contained 13 accessions from Thiès and 7 from Kédougou, while the second consisted of samples from Kédougou. Groups II and IV are homogeneous with only accessions from one region, Thiès and Kédougou respectively. Five individuals are admixtures from Diourbel region. 


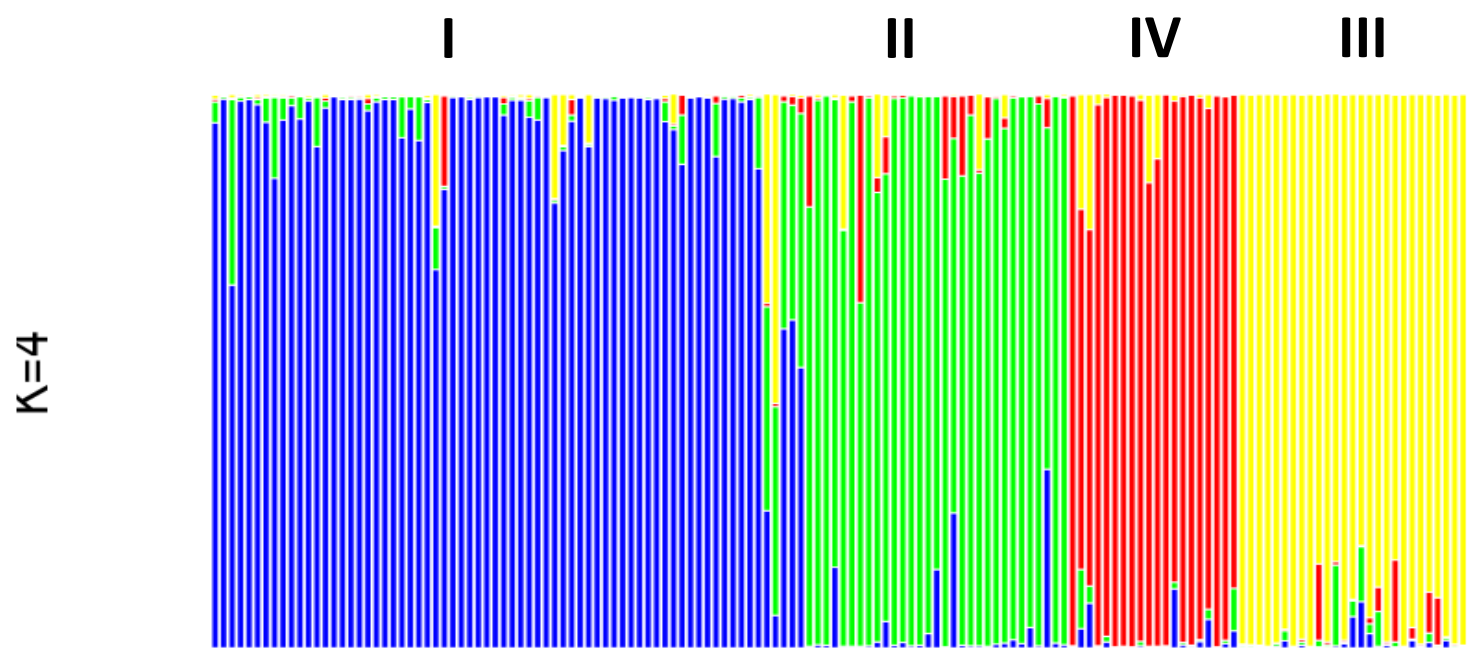

Figure 4. Genetic population structure predicted by STRUCTURE software.

\section{DISCUSSION}

All the markers used gave a net amplification of DNA fragments. The different makers have been properly chosen because of their specificity with sorghum. Moreover, they were polymorphic indicating that these markers are useful to assess the genetic structuration of sorghum.

The average of 4.6 alleles per locus recorded shows a relative diversity of sorghum in the regions investigated. The locus with 8 alleles has probably received low selection pressure compared to those with 3 alleles. The loci with the low number of allele are often quantitative traits loci which are suggested to breeding pressure.

The estimated diversity in this study is much smaller than the diversity observed in other sorghum populations. Indeed, Deu et al. (2008) used 28 SSRs markers to assess the genetic structure of 472 varieties from 76 villages in Niger. In their study, all the microsatellite loci were polymorphic and revealed 292 alleles, from 2 to 26 alleles per locus with an average of 10.43. Thirteen indigenous varieties were found in a single community in Zimbabwe (Oosterhout, 1997), 46 sorghum landraces identified by farmers in a village of North Cameroon (Barnaud et al., 2007), 76 varieties grown by farmers from three communities in northern Benin (Kayode' et al., 2006). The relatively low diversity recorded in our study might reflect our collection protocol which concerned only some selected regions of Senegal.

So, comparisons of genetic diversity between the above studies are difficult, since estimates such as allelic richness or expected heterozygosity depend on the sampling schemes, the number of surveyed SSR, the size of the SSR repeats and the location of the SSR on the genome (between coding or non-coding DNA regions) as highlighted by Deu et al. (2008).

The genetic distances values suggest that population genetic in Thiès, Diourbel and Kédougou are genetically closed. Indeed, each population is a bulk of individuals belonging to the three genetic groups as shown by the dendrogram. This explains the low Fst recorded when we compare sorghum populations from Thiès, Diourbel and Kédougou. Deu et al. (2008) found a Fst of 0.07 between regions in Niger. A weak genetic differentiation between regions has been reported (Ollitrault et al., 1997; Dje`et al., 1999; Nkongolo and Nsapato, 2003; Kayode' et al., 2006).

In the present study, the population of each region is spread in the different genetic group identified. That confirms the fact that farmers maintain traditional crop diversity to manage risks and increase their resilience in the face of strong environmental heterogeneity in both space and time, and numerous pest and diseases (Teshome et al., 1999; Deu et al., 2008). Similar results have been revealed on maize in Mexico (Bellon, 1997).

The dendrogram showed 4 groups if we consider the homogeneous subpopulation from Diourbel. STRUCTURE also identify 4 subpopulations and is known to work extremely well for inferring the number of clusters when clusters were not well-differentiated (Emily et al., 2006). In general, these populations and subpopulations include individuals from the three regions investigated designed with dendrogram and 
structure analysis.

This indicates that cultivars are not specific to a region. This result also could be explained by an important informal seed exchange between populations in the three regions and high adaptability of the collected cultivars to a range of agroecological zones in Senegal.

Several studies based on local collections reveal a lack of correlation between genetic diversity parameters and environmental factors (Ayana et al., 2000, 2001; Ghebru et al., 2002; Zongo et al., 2005) and a weak genetic differentiation between regions (Ollitrault et al., 1997; Dje`et al., 1999; Nkongolo and Nsapato, 2003; Kayode' et al., 2006). Deu et al. (2008) revealed differentiation between eastern and western Niger. Whereas the landraces collected in central Niger are intermixed in the two clusters.

Seed exchanges between farmers seem to explain a larger share of the observed genetic structure than climatic conditions. The fact that the farmers collectively maintain and rely on a large number of landraces to meet their production needs indicates that they must play a key role in future food security and conservation programs. We thus suggest, like others authors (Brush, 2000; Deu et al., 2008), that ethnic and social factors are key information to implement in situ sorghum conservation programs and conduct further ex situ collections of sorghum in subSaharan Africa.

According to STRUCTURE analysis, Groups II and IV are homogeneous with only accessions from one region, Thiès and Kédougou respectively. This illustrates the presence of landraces with specific genetic background in these regions. Moreover, the dispersion of individuals belonging to Thiès in group I shows significative germplasm diversity of sorghum in this area.

To capture the whole range of existing diversity of sorghum in Senegal, a genotyping of accessions in ICRISAT/India together with the present collection is necessary. Further researches should integrate molecular markers to botanical races and agro-morphological traits for a better understanding and management of the genetic resources of sorghum landraces in Senegal.

\section{ACKNOWLEDGEMENTS}

The authors thank the different people, who help in planning and sampling operations. They are also thankful to farmers who responded to the survey and provided us landraces used in this study. This work was supported by ICRISAT/Niger.

\section{REFERENCES}

ANSD. 2010. Agence Nationale de la Statistique et de la Démographie du Sénégal. www.ansd.sn

ANSD. 2018. Agence Nationale de la Statistique et de la Démographie du Sénégal. www.ansd.sn

Ayana, A., T. Bryngelsson and E. Bekele. 2000. Genetic variation of Ethiopian and Eritrean sorghum (Sorghum bicolor L. Moench) germplasm assessed by random amplified polymorphic DNA (RAPD). Genet Resour Crop Evol 47: 471-482.

Ayana, A, T. Bryngelsson and E. Bekele. 2001. Geographic and altitudinal allozyme variation in sorghum (Sorghum bicolor L. Moench) landraces from Ethiopia and Eritrea. Hereditas 135: 1-12.

Ba, K., E. Tine, J. Destain, N. Cissé and P. Thonart, 2010. Étude comparative des composés phénoliques, du pouvoir antioxydant de différentes variétés de sorgho sénégalais et des enzymes amylolytiques de leur malt. Biotechnologie, Agronomie, Société et Environnement, 14: 131-139.

Barnaud A, M. Deu E. Garine D. McKey and H.I. Joly. 2007. Local genetic diversity of sorghum in a village in northern Cameroon: structure and dynamics of landraces. Theoretical and Applied Genetics, 114: 237-248.

Barnaud A, G. Trigueros D. McKey and H.I. Joly. 2008. High outcrossing rates in fields with mixed sorghum landraces: how are landraces maintained? Heredity, 101: 445.

Bellon, M.R. 1997. On farm conservation as a process: an analysis ofits components. In: Sperling L, Loevinsohn M (eds) Using diversity: enhancing and maintaining genetic resources on-farm. IDRC, Ottawa, Canada.http://www.idrc.ca/en/ev85109-201-1-DO_TOPIC.html.

Brush, S.B. 2000. The issue of in situ conservation of genetic resources. In: Brush SB (eds) Genes in the field: on-farm conservation of crop diversity. IPGRI/ IDRC/Lewis Publishers, Boca Raton.

Deu, M., F. Rattunde and J. Chantereau. 2006. A global view of genetic diversity in cultivated sorghums using a core collection. Genome, 49: 168-180.

Deu, M., F. Sagnard, J. Chantereau, C. Calatayud, D. Hérault, C. Mariac and al. 2008. Niger-wide assessment of in situ sorghum genetic diversity with microsatellite markers. Theor. Appl. Genet. 116: 903-913.

Dje,'Y, D. Forcioli, M. Ater, C. Lefe`bvre, X. Vekemans. 1999. Assessing population genetic structure of 
sorghum landraces from North-western Morocco using allozyme and microsatellite markers. Theor Appl Genet 99: 157-163.

Dje,'Y., M. Heuertz, C. Lefe'bvre, X. Vekemans. 2000. Assessment of genetic diversity within and among germplasm accessions in cultivated sorghum using microsatellite markers. Theor Appl Genet 100: 918-925.

Doggett. H. 1988. Sorghum, 2nd edn. Longman Scientific and Technical, London, UK.

Latch, E. K., G. Dharmarajan, J.C. Glaubitz. And O.E. Rhodes. 2006. Relative performance of Bayesian clustering software for inferring population substructure and individual assignment at low levels of population differentiation. Conservation Genetics, 7: 295-302.

Ghebru, B., R.J. Schmidt and J.L. Bennetzen. 2002. Genetic diversity of Eritrean sorghum landraces assessed with simple sequence repeat (SSR) markers. Theor Appl Genet 105: 229-236.

Harlan, J. R. and A. Stemler. 1976. The races of sorghum in Africa. Origins of African plant domestication, 465478.

Kayode,'P.A.P., A.R. Linnemann, R.M.J. Nout, J.D. Hounhouigan, T.J. Stomph and M.J.M Smulders. 2006. Diversity and food quality properties of farmers' varieties of sorghum from Benin. J Sci Food Agric 86: 1032-1039.

litrault, O., J.L. Noyer, J. Chantereau, J.C. Glaszmann. 1997. Structureg génétique et dynamique des variétés traditionnelles de sorgho au Burkina Faso. In: Begic A (ed) Gestion des ressources génétiques de plantes en Afrique des savanes. IER-BRGSolagral, Bamako, Mali.

Menkir A., P. Goldsbrough and G. Ejeta. 1997. RAPD based assessment of genetic diversity in cultivated races of sorghum. Crop Sci 37: 564-56.

Mullet, J.E., R.R. Klein, and P.E. Klein. 2002. Sorghum bicolor-an important species for comparative grass genomics and a source of beneficial genes for agriculture. Current opinion in plant biology, 5: 118-121.

Nkongolo, K.K. and L. Nsapato. 2003. Genetic diversity in Sorghum bicolor (L.) Moench accessions from different ecogeographical regions in Malawi assessed with RAPDs. Genet Resour Crop Evol 50:149-156.

Oosterhout, S.V. 1997. What does in situ conservation mean in the life of a small-scale farmer? In: Sperling L, Loevinsohn M (eds) Using diversity: enhancing and maintaining genetic resources on-farm. IRDC, Ottawa, Canada.http://www.idrc.ca/en/ev85112-201-1-DO_TOPIC.html.

Peakall, R. and P.E. Smouse. 2012. GenAlEx 6.5: genetic analysis in Excel. Population genetic software for teaching and research-an update. Bioinformatics 28: 2537-2539.

Perrier, X. and J.P. Jacquemoud-Collet. 2006. DARwin Software. http://darwin.cirad.fr/darwin.

Schuelke, M. 2000. An economic method for the fluorescent labeling of PCR fragments. Nat Biotechnol 18: 233.

$\mathrm{R}$ Core Team. 2013. language and environment for statistical computing. R Foundation for Statistical Computing, Vienna, Austria. Available from http://www.R-project.org/.

Reenberg, A. 2001. Agricultural land use pattern dynamics in the Sudan-Sahel towards an eventdriven framework. Land Use Policy 18: 309-319.

Teshome A, L. Fahrig, J.K. Torrance, J.D. Lambert, T.J. Arnason, B.R. Baum. 1999. Maintenance of sorghum (Sorghum bicolor, Poaceae) landrace diversity by farmers' selection in Ethiopia. Econ Bot 53: 79-88.

Zongo, J.D., P.H. Gouyon, A. Sarr, M. Sandmeier. 2005. Genetic diversity and phylogenic relations among Sahelian sorghum accessions. Genet Resour Crop Evol 52: 869-878. 
Publisher's note: EScience Press remains neutral with regard to jurisdictional claims in published maps and institutional affiliations.

\begin{abstract}
(c) (7) Open Access This article is licensed under a Creative Commons Attribution 4.0 International License, which permits use, sharing, adaptation, distribution and reproduction in any medium or format, as long as you give appropriate credit to the original author(s) and the source, provide a link to the Creative Commons license and indicate if changes were made. The images or other third-party material in this article are included in the article's Creative Commons license, unless indicated otherwise in a credit line to the material. If material is not included in the article's Creative Commons license and your intended use is not permitted by statutory regulation or exceeds the permitted use, you will need to obtain permission directly from the copyright holder. To view a copy of this license, visit http://creativecommons.org/licenses/by/4.0/.
\end{abstract}

(c) The Author(s) 2019. 